\title{
Quantitative analysis of extracted phycobilin pigments in cyanobacteria - an assessment of spectrophotometric and spectrofluorometric methods
}

\author{
Monika Sobiechowska-Sasim • Joanna Stoń-Egiert • \\ Alicja Kosakowska
}

Received: 15 November 2013 /Revised and accepted: 15 January 2014 / Published online: 4 February 2014

(C) The Author(s) 2014. This article is published with open access at Springerlink.com

\begin{abstract}
Phycobilins are an important group of pigments that through complementary chromatic adaptation optimize the light-harvesting process in phytoplankton cells, exhibiting great potential as cyanobacteria species biomarkers. In their extracted form, concentrations of these water-soluble molecules are not easily determined using the chromatographic methods well suited to solvent-soluble pigments. Insights regarding the quantitative spectroscopic analysis of extracted phycobilins also remain limited. Here, we present an in-depth study of two methods that utilize the spectral properties of phycobilins in aqueous extracts. The technical work was carried out using high-purity standards of phycocyanin, phycoerythrin, and allophycocyanin. Calibration parameters for the spectrofluorometer and spectrophotometer were established. This analysis indicated the possibility of detecting pigments in concentrations ranging from 0.001 to $10 \mu \mathrm{g} \mathrm{cm}^{-3}$. Fluorescence data revealed a reproducibility of $95 \%$. The differences in detection limits between the two methods enable the presence of phycobilins to be investigated and their amounts to be monitored from oligotrophic to eutrophic aquatic environments.
\end{abstract}

Keywords Phycobilin concentration - Calibration · Absorbance $\cdot$ Fluorescence $\cdot$ Environmental monitoring

\section{Introduction}

Adequate information on phytoplankton community structure and functional diversity is essential to protect vulnerable

M. Sobiechowska-Sasim $(\bowtie) \cdot J$. Stoń-Egiert $(\bowtie) \cdot$ A. Kosakowska Institute of Oceanology, Polish Academy of Sciences, P.O. box 148, Powstańców Warszawy 55, 81-712 Sopot, Poland

e-mail: sobiechowska@iopan.gda.pl

e-mail: aston@iopan.gda.pl areas, such as densely populated coastal regions. To monitor the state of the environment, quick, cost-effective, and highquality information is required. The utilization of diagnostic pigments for the identification and quantification of different taxonomic groups is a well-known approach. Techniques using the optical properties of active components and their signatures in cells have been studied in detail (Roy et al. 2011; Sobiechowska et al. 2010; Stoń-Egiert et al. 2010). Most of the available methods for determining phytoplankton biomass and taxonomy focus on either chlorophylls or carotenoids; only in a few instances are data for phycobilins available (Lawrenz et al. 2011; Zimba 2012).

These water-soluble protein complexes - open-chain tetrapyrroles - are the major players in light harvesting in cyanobacteria, but they are also found in red algae, cryptomonads, prochlorophytes, and glaucocytophytes (Larkum 2003). The pigment system of cyanobacteria produces only a weak chlorophyll $a$ fluorescence signal. Fluorescence spectra arise mainly from photosystem II, so the fluorescence yield of phycobilins is very high, carrying a significant amount of spectral information that can be used to assess the abundance of cyanobacteria (Yentsch and Yentsch 1979). The availability of accurate concentrations for phycobilin pigments is essential for correlating reflectance with field population density; this is especially important in remote sensing. For example, the color sensors currently employed for the satellite imagery used to monitor large areas and to detect algal blooms are insufficiently sensitive to detect specific phycobilins (Woźniak et al. 2011).

In general, phycobilins absorb light in a series of overlapping peaks ranging from 450 to $660 \mathrm{~nm}$. Spectral variations in phycobiliproteins are caused by site-specific chromophoreprotein interactions (Bennet and Bogorad 1973; Zhao et al. 2011). The wavelengths characteristic of extracted pigments are not the same as for in vivo pigments in a membrane or 
bound to a protein in a phytoplankton cell, when absorption peaks are shifted to longer wavelengths (Beutler et al. 2002). All the spectroscopic methods that measure absorbance or fluorescence from phytoplankton use fixed wavelengths determined by the absorption/emission maximum.

In situ, in vivo fluorometry is a valuable tool for quickly obtaining a large quantity of spatial and temporal data for phytoplankton in the field, enabling cyanobacteria blooms to be detected in various aquatic ecosystems, especially in their coastal zones (Seppälä 2009). Typically, probes use wavelengths for fluorescence that are similar to those for the analysis of extracted pigments, but the available data obtained for phycobilin is expressed as the cell count per unit volume or as 'relative fluorescence units'.

Although the fluorescence of a whole cyanobacterium cell has been well studied (Babichenko et al. 2000; Seppälä 2009), no standardized method is available for extracting phycobilins. While the isolation of pigments from cells still poses a challenge, existing studies focus on methods suitable for phytoplankton monocultures (Jodłowska and Latała 2010; Lawrenz et al. 2011), the pigment content of which is usually higher than that of natural phytoplankton assemblages. The extraction and purification of phycobiliproteins from algae can be a complicated and lengthy procedure, influenced by temperature, extraction time, buffer, and pH (Viskari and Colyer 2003; Lawrenz et al. 2011). Thus, current research efforts are striving to modify and optimize this process, to minimize costs and maximize yields (Zimba 2012; Horváth et al. 2013). The most efficient pigment extraction procedures combine mechanical and chemical methods that lead to protein release. They include a variety of approaches, such as buffer solution treatment (Bennet and Bogorad 1973), lysozyme digestion (Steward and Farmer 1984), asolectin-CHAPS (Viskari and Colyer 2003), freezingthawing cycles, sonication, mechanical grinding (Lawrenz et al. 2011; Horváth et al. 2013), and capillary electrophoresis (Viskari and Colyer 2003). Accessible pigment content calculations rely principally on the equations introduced by Bennet and Bogorad (1973) and are applicable solely to absorbance data.

Our objectives in this paper were as follows: (1) to compare the analytical capabilities of two independent spectroscopic methods (spectrophotometric and fluorometric), applicable to the quantification of phycobilin pigments in aqueous extracts of phytoplankton; (2) to determine the calibration parameters enabling the detection limits of both methods to be established; and (3) to evaluate the suitability and usefulness of these methods for the analysis of phycobiliprotein concentrations in different types of samples from different ecosystems. To the best of our knowledge, such quantitative analytical procedures and the calculation of phycobilin concentrations have not been described in the literature. The rapid and precise quantitative estimate of cyanobacterial pigment concentrations in water resources may provide a timely measure of potential hazards due to the occurrence of toxic cyanobacteria.

\section{Material and methods}

\section{Monocultures}

The cyanobacteria cultures tested (see Table 1) include species that frequently occur in marine, coastal areas, estuaries, or lakes, and are often responsible for toxic summer blooms. Three of these species are known to contain large quantities of phycocyanin: Microcystis aeruginosa, Aphanizomenon flosaquae, and Nodularia spumigena, and one-Synechococcus $\mathrm{sp}$.- is rich in phycoerythrin. All the species were cultivated in the Marine Chemistry and Biochemistry Department's laboratory, Institute of Oceanology, Polish Academy of Sciences. Strains of N. spumigena (ZGNS1, current No. CCNP1401) were obtained from the University of Gdańsk, Laboratory of Biochemical Ecology of Microorganisms (Gdynia, Poland), A. flos-aquae came from the University of Helsinki, while M. aeruginosa (PCC 7820) and Synechococcus sp. (PCC 7002) were obtained from the Pasteur Culture Collection of Cyanobacteria (Paris, France). Phytoplankton strains were maintained as axenic or xenic cultures, and all cultures were grown in a sterilized medium (Table 1) in 100- $\mathrm{cm}^{3}$ Erlenmeyer flasks. The cultures were incubated for 10 days at $22{ }^{\circ} \mathrm{C} \pm 0.5$ under continuous illumination of $10 \mu \mathrm{mol}$ photons $\mathrm{m}^{-2} \mathrm{~s}^{-1}$ provided by cool white fluorescence bulbs (Kosakowska et al. 2007).

Culture aliquots filtered in replicates of $2-10 \mathrm{~cm}^{3}$, depending on cell density, were concentrated on Whatman glass fiber filters of $0.7-\mu \mathrm{m}$ nominal pore size and $25-\mathrm{mm}$ diameter (GF/F). Overall, two sets of filters for each species were obtained: one for phycobilins and one for chlorophyll $a$ quantification. The collected material was treated in accordance with pigment analysis protocols: Each filter was folded, wrapped in white paper and aluminum foil, frozen, and stored at $-80{ }^{\circ} \mathrm{C}$ for further analysis. For the present work, two experiments involving monoculture extracts were designed: one to confirm the presence of higher concentrations of phycobilin pigments in monoculture extracts, the other to compare the results for a pure cyanobacterial extract versus those spiked with phycobilin standard(s). For this purpose, phycocyanin (PC) $\left(4 \mu \mathrm{g} \mathrm{cm}^{-3}\right)$ and phycoerythrin (PE) $\left(5 \mu \mathrm{g} \mathrm{cm}^{-3}\right)$ were added to $8 \mathrm{~cm}^{3}$ of $M$. aeruginosa and Synechococcus sp. extracts, respectively.

\section{Pigment extraction}

The extraction protocol for phycobiliproteins was carried out according to Steward and Farmer (1984). The extraction buffer consisted of 0.25-M Trizma base (Sigma-Aldrich), hydrated 10-mM disodium EDTA $\left(2 \mathrm{H}_{2} \mathrm{O}\right)$ (Sigma-Aldrich) and 2$\mathrm{mg} \mathrm{cm}{ }^{-3}$ lysozyme (Merck). All three components were dissolved separately in Milli-Q distilled water (Millipore) before being combined as a single solution. According to this 
Table 1 Main characteristics of cyanobacteria strains chosen for studying their phycobilin and chlorophyll $a$ concentrations

\begin{tabular}{|c|c|c|c|c|c|}
\hline Cyanobacteria species & Toxins & Life form & Habitat & $\begin{array}{l}\text { Growth } \\
\text { medium }\end{array}$ & References \\
\hline Microcystis aeruginosa & Microcystin & Spherical cells-forming colonies & Freshwater, brackish & 616 & \multirow{4}{*}{$\begin{array}{l}\text { Cronberg et al. } 2003 \\
\text { Mazur-Marzec } \\
\text { et al. } 2006\end{array}$} \\
\hline Aphanizomenon flos-aquae & $\begin{array}{l}\text { Saxitoxin } \\
\text { Neosaxitoxin }\end{array}$ & Filamentous trichomes & Marine, brackish & 616 & \\
\hline Nodularia spumigena & Nodularin & Filamentous trichomes & Marine, brackish, estuaries & BG11 & \\
\hline Synechococcus sp. & Heamolytic & $\begin{array}{l}\text { Oval, cylindrical cells, irregular } \\
\text { clusters picoplankton }\end{array}$ & Marine, brackish & MI & \\
\hline
\end{tabular}

methodology, the initial $\mathrm{pH} 9$ was acidified with hydrochloric acid, finally adjusted to precisely $\mathrm{pH}$ 5.5. The solution was set aside for approximately $3 \mathrm{~h}$ to allow it to reach equilibrium. The extraction buffer was always prepared fresh on the day of the analysis, stored in the dark at $4{ }^{\circ} \mathrm{C}$, and was used for no longer than $48 \mathrm{~h}$ to prepare phycobilin standards, their dilutions and finally to extract pigments from the cyanobacterial cells.

Partially thawed filters were analyzed for their phycobiliprotein content by extracting them in buffer solution. These procedures took place in a darkened laboratory, and a combination of a gentle mechanical grinding and enzymatic (lysozyme) reaction was employed to disintegrate cell walls and improve pigment extraction efficiency. The material from each vial was vortexed (Heidolph Instruments, Germany), incubated in a dry block heat bath (Thermoleader, UniEquip) at $37^{\circ} \mathrm{C}$ for $2 \mathrm{~h}$, after which the samples were stored in the dark at $4{ }^{\circ} \mathrm{C}$ for $24 \mathrm{~h}$. Thereafter, the samples were centrifuged (Beckman GS-6R) at 2,800 $\times g$ for $15 \mathrm{~min}$. In practice, the overall extraction time for phycobilins (from cell disintegration to pigment analysis) did not exceed $30 \mathrm{~h}$. To evaluate extraction efficiency, an additional experiment consisting of two extraction cycles was carried out. The conditions that followed the isolation procedure described above were maintained throughout the course of the test.

Filters with material intended for the analysis of chlorophyll $a$ and phycobilins were analyzed simultaneously. Chlorophyll $a$ was extracted according to the standard procedures that recommend using $90 \%$ acetone as a solvent by mechanical grinding and sonication ( $2 \mathrm{~min}, 20 \mathrm{kHz}$, Ultrasonic Homogenizer 4710 Series, Cole Parmer Instruments) in the dark at $4{ }^{\circ} \mathrm{C}$ for $2 \mathrm{~h}$. The extract was centrifuged $\left(20 \mathrm{~min}, 5^{\circ} \mathrm{C}, 3,210 \times \mathrm{g}\right.$, Beckman, GS-6R) to remove the filters and cell debris.

In our study, to ensure applicability of this procedure to the routine analysis of phycobilins, the aspect of multiple extractions was neglected. Ultimately, a single cycle of extraction was applied to all samples. Pigment concentrations were assessed using the equations by Jeffrey and Humphrey (1975) for chlorophyll $a$ (chl $a$ ) and by Mantoura and Repeta (1997) for phycobilins.

Phycobilin standards - calibration and dilution series

Phycobilin standards (ProZyme Inc., USA) were used to conduct regular calibration experiments $(n=5)$ with replicates $(n=3)$ for each of the two analytical techniques. Detailed information regarding the purchased reference material is summarized in Table 2.

The pigments - $5 \mathrm{mg}$ of $\mathrm{PC}$ (PhycoPro ${ }^{\mathrm{TM}} \mathrm{C}$ Phycocyanin), $5 \mathrm{mg}$ of APC (PhycoPro ${ }^{\text {TM }}$ Allophycocyanin), and $10 \mathrm{mg}$ of PE (PhycoPro ${ }^{\mathrm{TM}}$ R-Phycoerythrin) - were purchased in two lots (in 2010 and 2012) at respective concentrations of 21.2 and $25.1,22.1$ and 23.8 , and $20.0 \mathrm{mg} \mathrm{cm} \mathrm{cm}^{-3}$. The solutions were supplied as suspensions in $60 \%$ ammonium sulfate, $50-\mathrm{mM}$ potassium phosphate (pH 7.0) and stored in the dark at $4{ }^{\circ} \mathrm{C}$, as recommended by the supplier.

Table 2 Summary of information provided by the certificate of analysis for phycobiliproteins (ProZyme, Inc.)

\begin{tabular}{|c|c|c|c|c|c|c|c|c|c|}
\hline \multirow[t]{2}{*}{ Phycobiliprotein } & \multirow[t]{2}{*}{ Code } & \multirow[t]{2}{*}{ MW (kDa) } & \multirow{2}{*}{$\begin{array}{l}\text { Protein } \\
\text { subunits }\end{array}$} & \multirow[t]{2}{*}{$\mathrm{Abs}_{\max }(\mathrm{nm})$} & \multirow[t]{2}{*}{$\mathrm{Em}_{\text {max }}(\mathrm{nm})$} & \multicolumn{2}{|l|}{ Purity } & \multirow{2}{*}{$\begin{array}{l}\text { Extinc. } \\
\text { coeff. } E_{\lambda, \max }^{1 \%}\end{array}$} & \multirow[t]{2}{*}{ Origin } \\
\hline & & & & & & $\mathrm{A}_{\lambda \max } / \mathrm{A}_{280}{ }^{\mathrm{a}}$ & $\mathrm{A}_{620} / \mathrm{A}_{566}{ }^{\mathrm{b}}$ & & \\
\hline C-Phycocyanin & PB11 & 232 & $(\alpha \beta)_{6}$ & 620 & 647 & 4.68 & n.a. & 70 & Spirulina platensi \\
\hline R-Phycoerythrin & PB31 & 240 & $(\alpha \beta)_{6} \gamma$ & $496-566$ & 576 & 5.61 & $<0.005$ & 82 & Red algae \\
\hline Allophycocyanin & PB20 & 104 & $(\alpha \beta)_{3}$ & $648-652$ & 660 & 5.3 & n.a. & 73 & Spirulina platensi \\
\hline
\end{tabular}

n.a. not available

${ }^{\text {a }}$ Indicative of the purity of the preparation with respect to most forms of contaminating protein. Absorbance at $280 \mathrm{~nm}$ in these preparations is primarily due to aromatic amino acids, and this is roughly proportional to the overall concentration of protein in solution, including C-PC, R-PE, and Allo-PC. The respective absorbances at 620,566 , and $652 \mathrm{~nm}$ reflect only concentration

${ }^{\mathrm{b}}$ Rough indicator of the level of contamination with R-PC 
Fig. 1 Examples of absorption (a) and fluorescence (b) spectra of phycobilin pigment standards obtained for known pigment standard concentrations.

Fluorescence emission spectra of PC obtained for excitation at $590 \mathrm{~nm}, \mathrm{APC}(600 \mathrm{~nm})$, and PE $(530 \mathrm{~nm})$ at a lamp intensity set to 800 . The marked wavelengths correspond to the maximum values of a absorbance and $\mathbf{b}$ emission

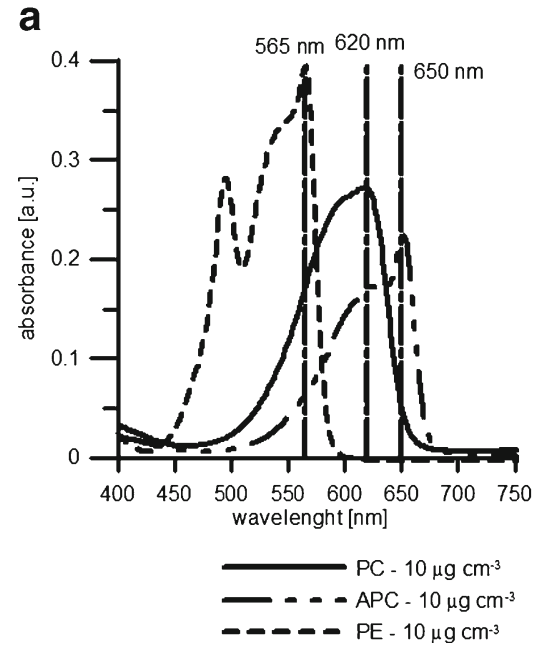

Highly concentrated single solutions were used to estimate the maximum concentration above which instrument drift would occur. Dilution series were prepared to evaluate calibration linearity and the minimum detectable quantity of a
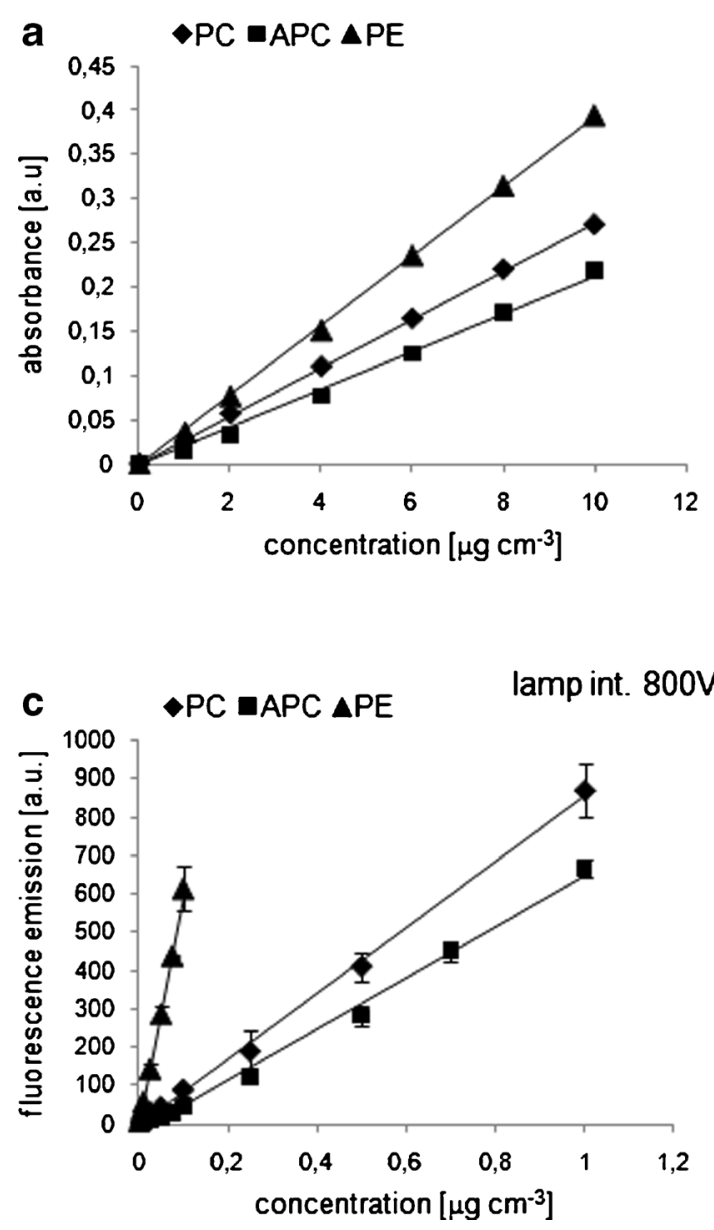

Fig. 2 Calibration curves of phycobiliprotein standards: phycocyanin (diamonds), allophycocyanin (squares), and phycoerythrin (triangles) obtained for a spectroscopic measurements (Spectrophotometer UV/Vis, Hitachi U-2800) and b-d spectrofluorometric measurements, substance. Stock solutions of single pigments and dilution series were prepared using appropriate amounts of each protein and extraction buffer as a solvent. Calibration curves were obtained for PC, PE, and APC using dilution series (from 6 to
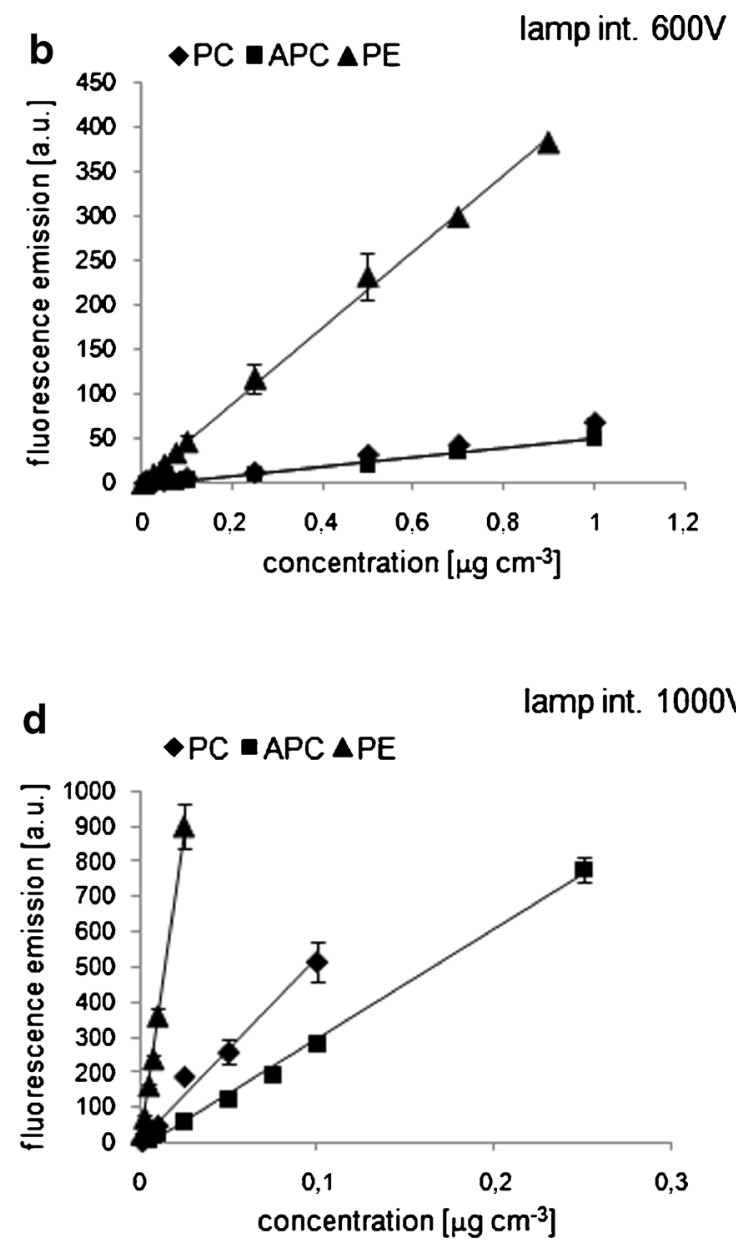

Fluorescence Spectrophotometer (Cary Eclipse, Varian, Agilent Technologies) for different lamp intensity settings: b $600 \mathrm{~V}$, c $800 \mathrm{~V}$, and d $1000 \mathrm{~V}$. The characteristic wavelengths for which instruments gave the illustrated responses are specified in Table 3 


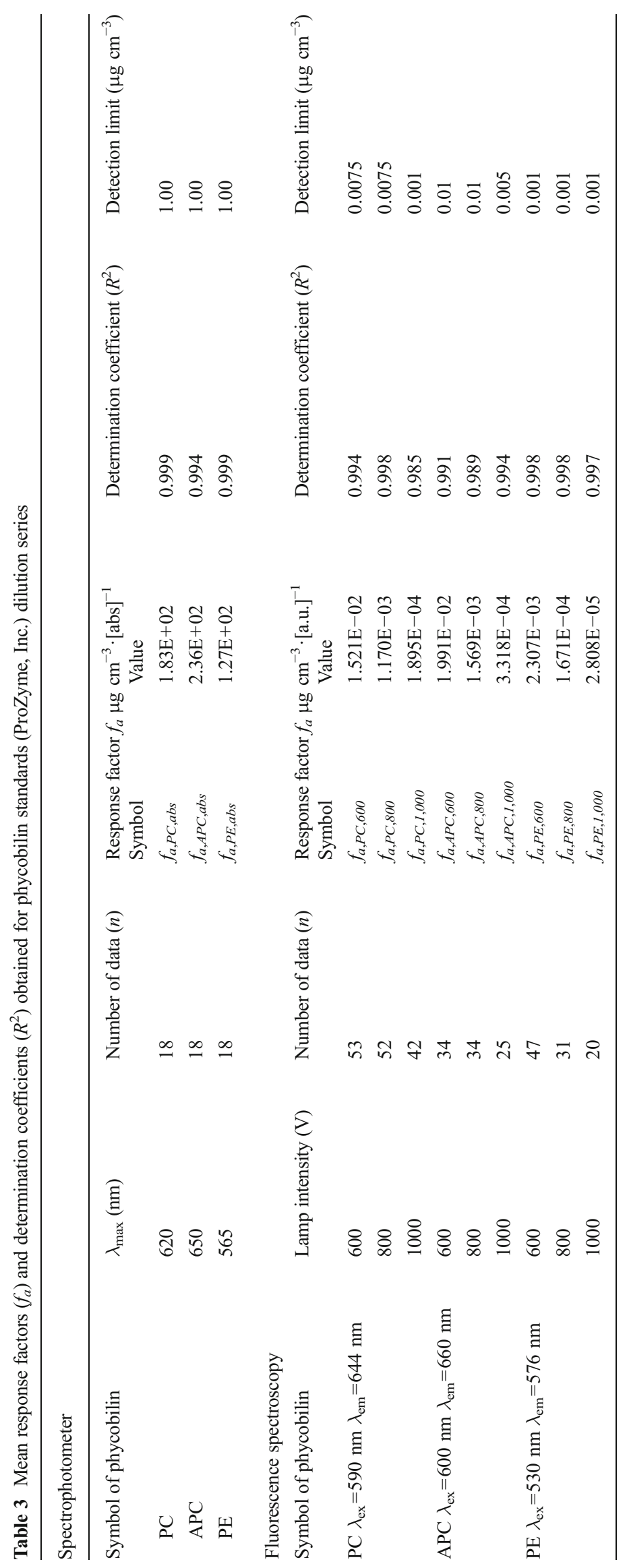




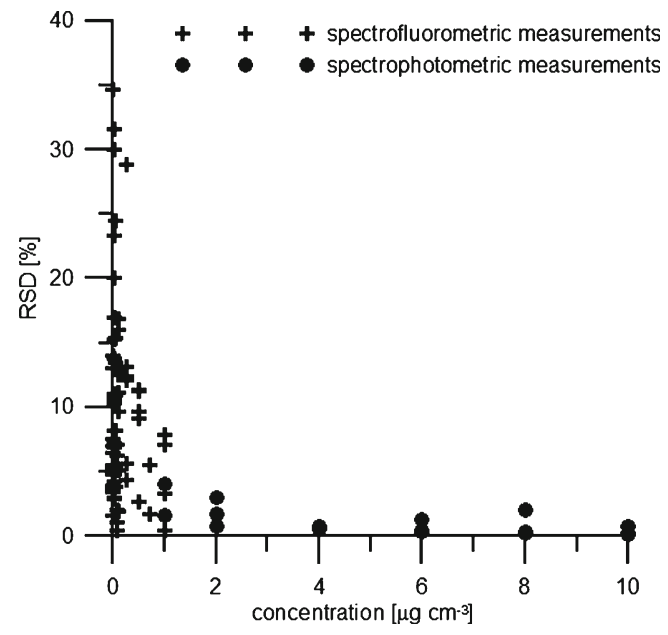

Fig. 3 Relative standard deviation (RSD) calculated for absorbance and fluorescence data for selected dilution series of phycobilin standards

13 levels) prepared in triplicate for each pigment. The concentration of the solutions ranged from 1 to $10 \mu \mathrm{g} \mathrm{cm}^{-3}$ for the absorbance measurements (Spectrophotometer UV/Vis Hitachi U-2800), from 0.001 to $1 \mu \mathrm{g} \mathrm{cm}^{-3}$ for PC and APC, and from 0.001 to $0.5 \mu \mathrm{g} \mathrm{cm}^{-3}$ for PE for the fluorometric measurements (Cary Eclipse, Varian, Agilent Technologies). Calibration was repeated several times for each pigment, using two sets of phycobilin standards. The number of repetitions (from $n=18$ to $n=53$ ) yielded a low scatter of apparatus response data, which is reflected by the low standard deviations of $<4.9 \%$ (discussed in "Results and discussion").

\section{Absorbance and fluorescence measurements}

The calibration parameters, i.e., response factor and detection limits, were determined for the two instruments. Analyses were carried out using a double-beam spectrometer (Spectrophotometer UV/Vis Hitachi U-2800) and a singlebeam, xenon lamp fluorescence spectrophotometer (Cary Eclipse, Varian, Agilent Technologies). Continuous spectra of absorbance (400-800 nm) and fluorescence emission readings (500-700 $\mathrm{nm}$ ) were collected using 5- and 1-cm glass and quartz cuvettes, respectively. Absorbance readings at $750 \mathrm{~nm}$ were used for background corrections. The emission intensity signal for the extraction buffer was subtracted from the values obtained for each sample. Emission spectra with a resolution of $2 \mathrm{~nm}$ were obtained for every $5 \mathrm{~nm}$ of excitation. The calibration analysis was carried out for three settings of the excitation signal and controlled by varying the intensity of the xenon lamp, set at 600,800 , and $1000 \mathrm{~V}$. The total run time for these settings would usually be about $15 \mathrm{~min}$, and the calibration was carried out at ambient temperature. The extraction buffer and $90 \%$ acetone were used as references for phycobilins and chlorophyll $a$, respectively.

\section{Results and discussion}

\section{Spectral characteristics of phycobilins}

The spectral characteristics of the target compounds were assessed in the course of a series of experiments. Examples of the absorbance and emission spectra of the phycobiliprotein standard (PC, APC, and PE) solutions are shown in Fig. 1. The spectrophotometric and spectrofluorometric signatures of single phycobilin pigments differ in their shape, $\lambda_{\max }$ number, and position. In the absorbance spectra, PC exhibits one maximum (at $620 \mathrm{~nm}$ ), whereas there are two peaks for PE (at 495 and $565 \mathrm{~nm}$ ) and for APC (at 615 and $650 \mathrm{~nm}$ ). The
Fig. 4 Series of fluorescence emission values obtained at $\lambda_{\mathrm{em}}=644 \mathrm{~nm}$ for a standard solution of PC (concentration $0.1 \mu \mathrm{g} \mathrm{cm}^{-3}$ ). The fluorescence spectrometer was set to different incident light intensities $\left(\lambda_{\mathrm{ex}}=590 \mathrm{~nm}\right): 600,800$, and 1000 V. Solid line mean value for a sequence, dotted line range of divergence from the mean value

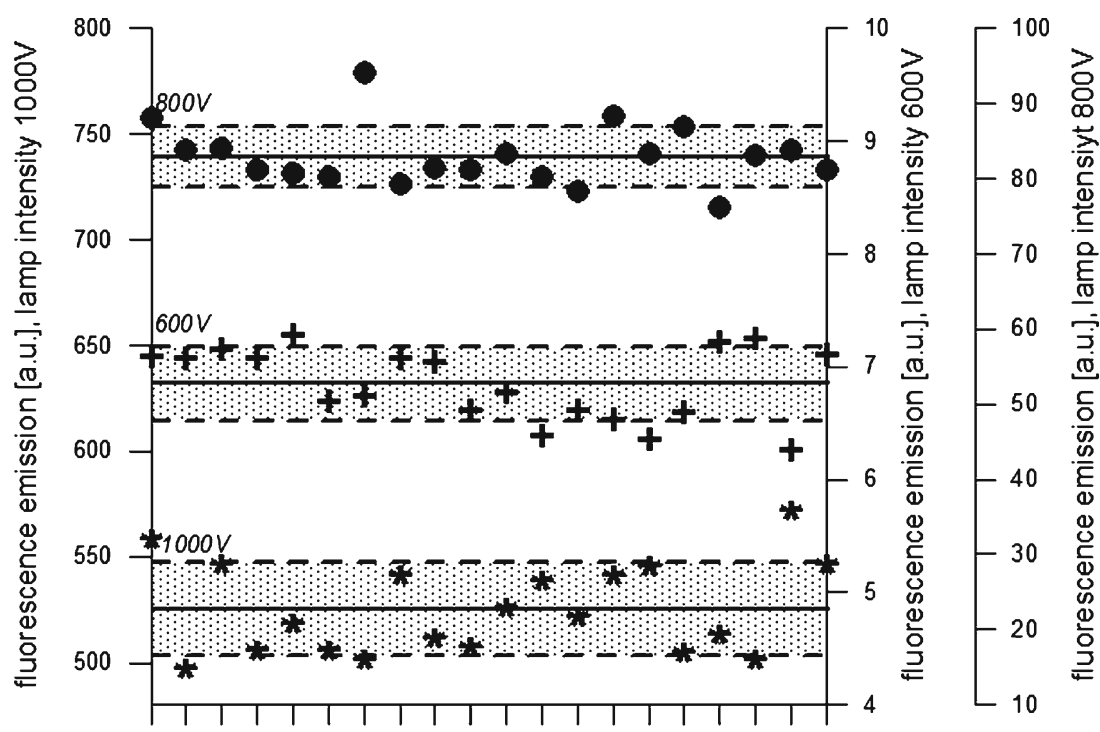

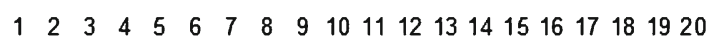
number in the sequence of data 

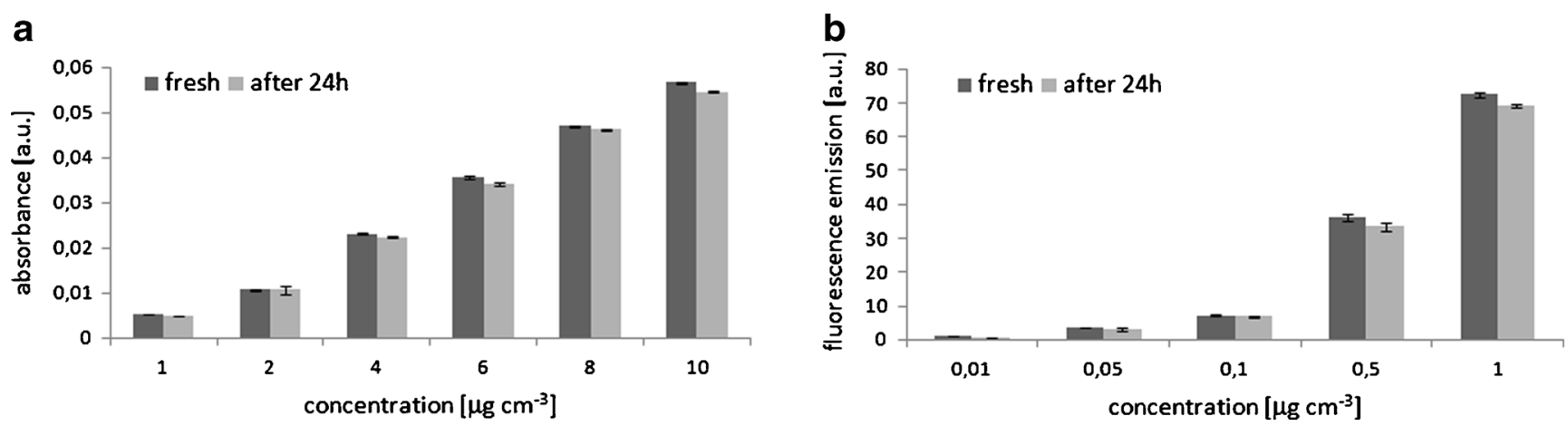

Fig. 5 Average temporal changes in $\mathbf{a}$ absorbance and $\mathbf{b}$ fluorescence response values (lamp settings $600 \mathrm{~V})$ for PC $(n=3)$. Fresh means measured $2 \mathrm{~h}$ after the solutions for extraction were prepared

emission spectra displayed single peaks for PC, PE, and APC at 644,576 , and $660 \mathrm{~nm}$, respectively. The spectra are in compliance with the data sheet included in the certificate of analysis, provided by the pigment standards supplier (ProZyme, Inc.).

Based on the information derived from spectra, the maximum absorbance wavelength $\left(\lambda_{\max }\right)$ and the maximum emission wavelength $\left(\lambda_{\mathrm{em}}\right)$ for a specific excitation wavelength $\left(\lambda_{\text {ex }}\right)$ for single compounds were chosen for further analysis. Thus, the following wavelengths were selected for the spectrophotometric measurements: $620 \mathrm{~nm}$ for PC, $650 \mathrm{~nm}$ for $\mathrm{APC}$, and $565 \mathrm{~nm}$ for PE. For the fluorescence measurements, $\mathrm{PC}$ was investigated by exciting the molecule at $590 \mathrm{~nm}$ (maximum of emission $\lambda_{\mathrm{em}}=644 \mathrm{~nm}$ ), APC emission spectra were obtained from excitation wavelengths set at $600 \mathrm{~nm}$ $\left(\lambda_{\mathrm{em}}=660 \mathrm{~nm}\right)$, and PE emission spectra at $576 \mathrm{~nm}$ were obtained from excitation at $530 \mathrm{~nm}$.

\section{Calibration parameters and detection capabilities}

The series of experiments and information gained regarding phycobilin concentration ranges generated multiple-point calibration curves for both measuring techniques (Fig. 2). Based on the equations obtained, calibration coefficients such as response factors, detection limits, method sensitivity, and analytical precision for the target compounds were established for different measuring conditions (Table 3). Knowledge of response factors is necessary for determining the concentrations of target compounds using the external standardization equation method (Mantoura and Repeta 1997). Values of coefficients $f_{a}$ correspond to the slope of the linear function where concentration is plotted against instrument response. Curves were obtained in a series of experiments carried out from 2010 to 2013; the amount of calibration data points was thus substantial. The calibration curves yielded satisfactory correlation coefficients $\left(R^{2}\right)$, between 0.985 and 0.999 . The use of different light intensity settings enabled the concentration to be specified with coefficients $f_{a}$ changing by one order of magnitude. The response factors for phycocyanin and allophycocyanin - compounds with a similar chemical structure and similar shape of fluorescence spectrum-were comparable for different lamp intensity settings (see Table 3).

Phycoerythrin exhibited greater sensitivity with the fluorescence technique compared to the other phycobiliproteins analyzed in this study, which was reflected by the lower detection limits obtained under the same measurement conditions (the same lamp intensity settings), and the 6-12 times smaller values of the calibration curve slopes. Overall, the concentration range for the two analytical methods used in our study revealed a difference in sensitivity of five orders of magnitude: The minimum detection limit for the spectrofluorometer appears to overlap the quantitation maximum for the

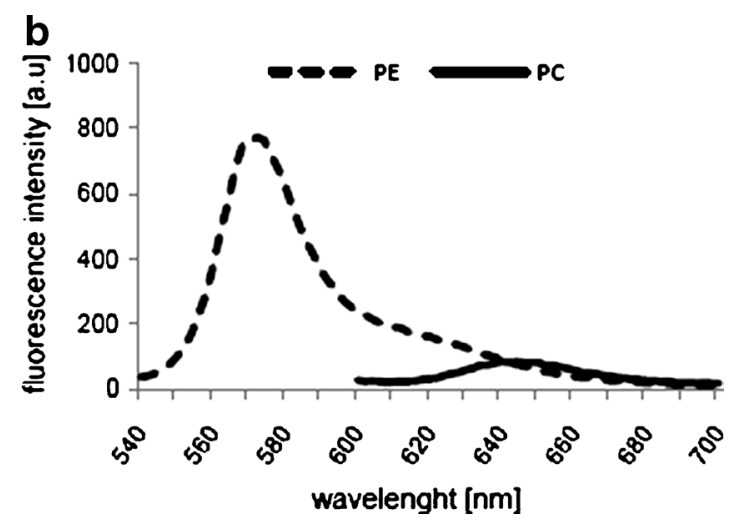

Fig. 6 Emission spectra obtained for selected monoculture extracts. a Microcystis aeruginosa. b Synechococcus sp. 
Fig. 7 Phycocyanin concentration $\left(\mu \mathrm{g} \mathrm{cm}^{-3}\right)$ and relative $\mathrm{PC} / \mathrm{chl} a$ ratios determined for cyanobacteria monoculture extracts.

Comparison of data assessed using two analytical techniques: spectrophotometry (blue) and spectrofluorometry (red)
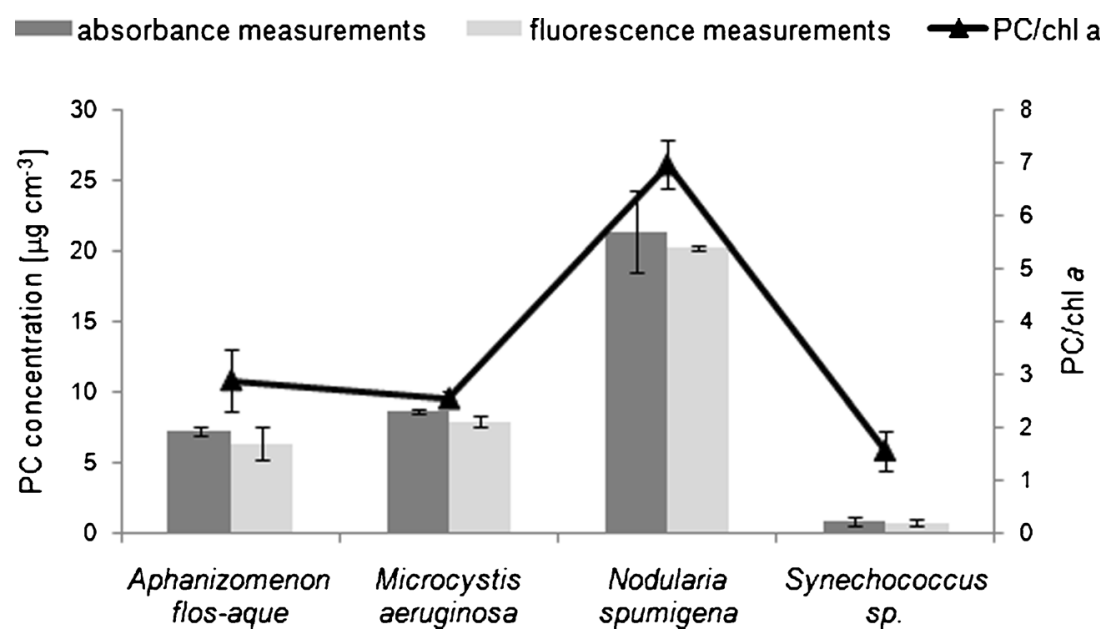

spectrophotometer. This analysis indicates that phycobilins present in amounts from 0.001 to $10 \mu \mathrm{g} \mathrm{cm}^{-3}$ are potentially detectable, enabling the occurrence of these pigments to be investigated in different ecosystems where microorganism cells contain trace amounts of phycobiliproteins.

As shown in Fig. 3, the relative standard deviation (RSD) obtained for the separate dilution series of phycobilin standards ranged from 0.5 to $34.7 \%$ for the absorbance data $(n=18)$ and from 0.15 to $4 \%$ for the fluorescence data $(n=75)$. The mean RSD was $9.6 \%( \pm 7.3 \%)$ for the fluorescence readings and $1.1 \%( \pm 1.1 \%)$ for the spectroscopic data. The highest RSDs $(>20 \%, n=7)$ are related to the lowest concentrations (from 0.0075 to $0.05 \mu \mathrm{g} \mathrm{cm}^{-3}$ ), whereas RSD $<10 \%$ (mean $=5.1 \pm 2.4 \%$ ) was calculated for more than $50 \%$ of the data points obtained $(n=45)$.

\section{Reproducibility}

The sensitivity and analytical precision of the method were specified on the basis of a series of measurements $(n=20)$ carried out at selected light excitation and emission intensities. The reproducibility of the instrument response (here, the fluorescence emission intensity) obtained for one of the pigment

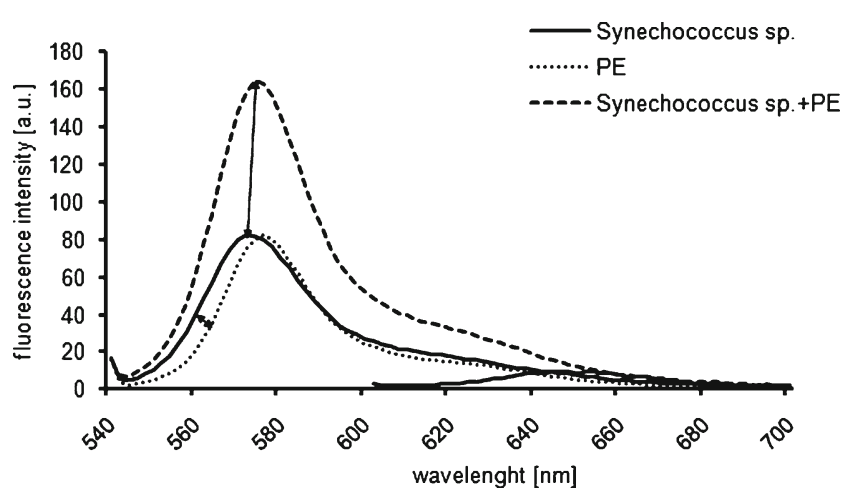

Fig. 8 Emission spectra obtained for a PE-rich cyanobacteria monoculture standards (PC) at different light intensities is presented in Fig. 4. A certain concentration $\left(0.1 \mu \mathrm{g} \mathrm{cm}^{-3}\right)$ of analyte was matched in such a way that the intensity of the instrument response to excitation achieved at 600,800 , and $1000 \mathrm{~V}$ would not exceed the detector's range of sensitivity. The response intensities for $\lambda=644 \mathrm{~nm}$ ranged from a mean value of $6.8 \pm 0.3$ at $600 \mathrm{~V}$ to $83.0 \pm 4.0$ at $800 \mathrm{~V}$ and $525.2 \pm 21.8$ for $1000 \mathrm{~V}$. The RSD calculated for these observations was the lowest (4.14\%) for the intensity of $1000 \mathrm{~V}$; the values obtained for 800 and $600 \mathrm{~V}$ were at a similar level- 4.9 and $4.8 \%$, respectively. Based on the number of observations for a PC standard solution, the average precision error of the fluorometric method was $4.6 \%$.

Temporal stability of phycobilins

During calibration, the temporal variability of the fluorescence response for standard solutions of PC, APC, and PE was also examined. We compared the results obtained 2 and $24 \mathrm{~h}$ following the preparation of the standard extracts (Fig. 5). There was a slight decrease in emission intensity with time. The decline in pigment concentration for PC ranged from 4.3 to $13.4 \%$ (mean $8.8 \pm 4.25 \%$ ), for PE from 0.5 to $5 \%$ (mean $3.1 \pm 3.15 \%$ ), and for APC from 13.2 to $15 \%$ (mean $14.2 \pm$ $0.95 \%$ ). The highest variability seemed to go hand in hand with the lowest concentration.

For the absorbance measurements, only a slight decrease was observed after $24 \mathrm{~h}$ relative to the absorbance of freshly prepared solutions: for PC from 0.03 to $9.2 \%(3.4 \pm 2.9 \%)$ (Fig. 5a), for APC from 0 to $8.6 \%$ (mean $2.4 \pm 3.5 \%$ ), and for PE from 0 to $1 \%$ (mean $0.4 \pm 0.5 \%$ ).

An interesting observation was made concerning the extraction buffer and its stability over time. Compared to the initial conditions (immediately after the solution was prepared), there was an approximately twofold increase in emission intensity $2-$ $3 \mathrm{~h}$ later. After this dynamic change, the signal from the extraction solution remained stable for at least 1 day. The 
inference from this is that the extraction buffer should be prepared fresh but not used right away. We recommend a period of approximately $3 \mathrm{~h}$ to allow the reaction to reach equilibrium. Since a spectrophotometer is known to give a less intensive response than a fluorometer, no such observation regarding the extraction solution was made in the case of absorbance.

\section{Phycobiliproteins in monocultures}

The suitability of the two analytical methods for determining the extracted phycobilins was examined. The pigment content in cells was assessed in four species of cyanobacteria (details in the "Pigment extraction" section). The improvement in extraction efficiency attributable to re-extraction, suggested by Horváth et al. (2013), was examined for two coccoid cyanobacteria cultures: Synechococcus sp. and M. aeruginosa. A second round of pigment extraction from cells yielded on average an additional $10.5 \%$ of PE $(n=6)$ and $6.4 \%$ of PC $(n=6)$ for PErich species and $10.4 \%$ of PC $(n=6)$ for M. aeruginosa. The results are comparable with the values presented by other authors (Zimba 2012). The coefficient of variation for replicates was $20 \%$ for PC (for both cultures) and $11 \%$ for PE (Synechococcus sp.). Qualitatively, the phycobilins found in extracts of cultures matched the characteristics of the pigments (Seppälä 2009; Jodłowska and Latała 2010): PC was found in all extracts, occurring more abundantly than $\mathrm{PE}$ in three of the four species analyzed, giving a strong signal and a characteristic reddish colouration in Synechococcus sp.; APC was not found (Figs. 6 and 7).

The phycobilin concentration was calculated using two external calibration equations that gave comparable results. The difference of $8.1 \%( \pm 7.7 \%)$ between the absorbance- and fluorescence-based measurements obtained for PC indicates an overall high accuracy. The PC concentration in the material analyzed ranged from $0.79 \mu \mathrm{g} \mathrm{cm}^{-3}$ for Synechococcus sp. to $20.22 \mu \mathrm{g} \mathrm{cm}^{-3}$ for $N$. spumigena. Figure 7 illustrates the PC concentrations obtained with the two analytical methods. The relative pigment content in cells varied from 1.6 to 7 for $\mathrm{PC}$, but was 2.1 for PE, which was identified only in red Synechococcus sp. The high phycobilin/chl $a$ ratios confirm that accessory pigments as photosynthetic antennae in photosynthetic apparatus of tested species, as demonstrated earlier by Beutler et al. (2003). Phycobilins (chromophores) are known to be present at higher concentrations than chlorophylls in many cyanobacteria species and red algae (Nobel 2009).

In nature, allophycocyanin is present at significantly lower levels than phycocyanin or phycoerythrin, accounting on a weight basis for approximately $10 \%$ of the total cellular phycobiliprotein. The APC absorption maximum in whole cells or a crude extract is largely masked by the much greater absorbance of PC (Ting et al. 2002). An approach such as deconvolution may be a possible means of overcoming the method selectivity problem (MacColl 1991).
Monoculture extracts spiked with phycobilin standards revealed some interesting yet unexpected insights (Fig. 8). Firstly, the spectrum obtained from a standard solution of specific pigments differs slightly from that obtained for a monoculture extract, naturally containing pigments as well as other cellular components (e.g., different proteins) that can alter the shape of the spectrum. Secondly, spectrum height (the signal intensity) reflects the quantity of analyte and increases proportionally, which is especially evident in the case of a cyanobacteria extract spiked with a standard pigment solution. Spectrophotometry was not sensitive enough to produce an absorbance signal falling within our detection limit. On the other hand, we were able to apply spectrofluorometry to quantify phycobilin pigments extracted from phytoplankton cells.

\section{Conclusions}

In this study, to assess the quantitative analysis of phycobilins, we verified and confirmed the poorer sensitivity of spectrophotometric methods compared with spectrofluorometry. We suggest that the former approach would be more appropriate for highly concentrated, monoculture extracts, whereas phycobilins extracted from natural waters can be identified spectrofluorometrically. Nonetheless, all the necessary steps in the analytical process should be followed in order to obtain qualitatively and quantitatively reliable methods, and that includes careful consideration of particular study needs and priorities. The determination of extracted phycobilin pigments and their application as additional biomarkers is a promising approach for the routine monitoring of cyanobacteria in coastal, densely inhabited, and less-populated aquatic environments.

Acknowledgments The authors would like to thank the Marine Biochemistry Laboratory technicians for their assistance during this study. This research was funded by the project "Satellite Monitoring of the Baltic Sea Environment - SatBałtyk (2010-2014)", and by the European Union through the European Regional Development Fund contract no. POIG 01.01.02-22-011/09. This work was also supported by statutory research grants from the Institute of Oceanology, Polish Academy of Sciences, and the Polish Ministry of Science and Higher Education.

Open Access This article is distributed under the terms of the Creative Commons Attribution License which permits any use, distribution, and reproduction in any medium, provided the original author(s) and the source are credited.

\section{References}

Babichenko S, Leeben A, Poryvkina L, van der Vagt R, de Vos F (2000) Fluorescent screening of phytoplankton and organic compounds in sea water. J Environ Monit 2:378-383 
Bennet A, Bogorad L (1973) Complementary chromatic adaptation in filamentous blue-green alga. J Cell Biol 58:419-435

Beutler M, Wiltshire KH, Meyer B, Moldaenke C, Lüring C, Meyerhöfer M, Hansen U-P, Dau H (2002) A fluorometric method for the differentiation of algal populations in vivo and in situ. Photosynth Res 72:39-53

Beutler M, Wiltshire KH, Arpa M, Krused J, Reinekea C, Moldaenke C, Hansen U-P (2003) A reduced model of the fluorescence from the cyanobacterial photosynthetic apparatus designed for the in situ detection of cyanobacteria. Biochim Biophys Acta 1604:33-46

Cronberg G, Carpenter EJ, Carmichael WW (2003) Taxonomy of harmful cyanobacteria. In: Hallegraeff GM, Anderson DM, Cembella AD (eds) Manual on harmful marine microalgae. UNESCO Publication, Paris, pp 523-562

Horváth H, Kovács AW, Riddick C, Présing M (2013) Extraction methods for phycocyanin determination in freshwater filamentous cyanobacteria and their application in a shallow lake. Eur J Phycol 48:278-286

Jeffrey SW, Humphrey GF (1975) New spectrophotometric equations for determining chlorophylls $a, b, c_{1}$ and $c_{2}$ in higher plants, algae and natural phytoplankton. Biochem Physiol Pflanzen 167:191-194

Jodłowska S, Latała A (2010) Photoacclimation strategies in the toxic cyanobacterium Nodularia spumingena (Nostocales, Cyanobacteria). Phycologia 49:201-211

Kosakowska A, Nędzi M, Pempkowiak J (2007) Responses of the toxic cyanobacterium Microcystis aeruginosa to iron and humic substances. Plant Physiol Biochem 45:365-370

Larkum AWD (2003) Light harvesting systems in algae. In: Larkum AWD, Douglas SE, Raven JA (eds) Photosynthesis in algae. Kluwer, Dordrecht, pp 277-289

Lawrenz E, Fedewa EJ, Richardson TL (2011) Extraction protocols for the quantification of phycobilins in aqueous phytoplankton extracts. J Appl Phycol 23:865-871

MacColl R (1991) Fluorescence studies on R-phycoerythrin and Cphycoerythrin. J Fluorescence 1:135-140

Mantoura RFC, Repeta DJ (1997) Calibration methods for HPLC. In: Jeffrey S, Mantoura R, Wright S (eds) Phytoplankton pigments in oceanography: guidelines to modern methods. UNESCO Publication, Paris, pp 407-428

Mazur-Marzec H, Krężel A, Kobos J, Pliński M (2006) Toxic Nodularia spumigena blooms in the coastal waters of the Gulf of Gdańsk: a ten year survey. Oceanologia 48:255-273
Nobel SP (2009) Photochemistry of photosynthesis - other photosynthetic pigments. In: Nobel SP (ed) Physicochemical and environmental plant physiology, Fourth edn. Academic Press, Oxford, pp 238-244

Roy S, Llewellyn CA, Egeland ES, Johnsen G (2011) Phytoplankton pigments: characterization, chemotaxonomy and applications in oceanography. Cambridge University Press, Cambridge

Seppälä J (2009) Fluorescence properties of Baltic sea phytoplankton. Monographs of the Boreal environment research (34). Edita Prima Ltd, Helsinki, p 83

Sobiechowska M, Bridoux M, Ferreira Ferreira AH, PerezFuentetaja A, Alben K (2010) Biomarkers of algal populations in phytoplankton, filamentous alga, and sediments from the eastern basin of Lake Erie 2003-2005. J Great Lakes Res 36:298-311

Steward DE, Farmer FH (1984) Extraction, identification, and quantitation of phycobiliprotein pigments in phototrophic plankton. Limnol Oceanogr 29:392-397

Stoń-Egiert J, Łotocka M, Ostrowska M, Kosakowska A (2010) The influence of biotic factors on phytoplankton pigment composition and resources in Baltic ecosystems: new analytical results. Oceanologia 52:101-125

Ting CS, Rocap G, King J, Chisholm SW (2002) Cyanobacterial photosynthesis in the oceans: the origins and significance of divergent light-harvesting strategies. Trends Microbiol 10:134142

Viskari PJ, Colyer CL (2003) Rapid extraction of phycobiliproteins from cultured cyanobacteria samples. Anal Biochem 319:263-271

Woźniak B, Bradtke K, Darecki M, Dera J et al (2011) SatBaltic - a Baltic environmental satellite remote sensing system - an ongoing project in Poland part 2: practical applicability and preliminary results. Oceanologia 53:925-958

Yentsch CS, Yentsch CM (1979) Fluorescence spectral signatures: the characterization of phytoplankton populations by the use of excitation and emission spectra. J Mar Res 37:471-483

Zhao KH, Porra RJ, Scheer H (2011) Phycobiliproteins. In: Roy S, Llewellyn CA, Egeland ES, Johnsen G (eds) Phytoplankton pigments: characterization, chemotaxonomy and applications in oceanography. Cambridge University Press, Cambridge, pp 375411

Zimba PV (2012) An improved phycobilin extraction method. Harmful Algae 17:35-39 